\title{
KEBERHASILAN TERAPI SPRITUAL EMOTIONAL TECHNIQUE (SEFT) TERHADAP PENURUNAN TEKANAN DARAH DI DESA PANDAU JAYA KEC.SIAK HULU KAB.KAMPAR Maswarni $^{1)^{*}}$, Hayana ${ }^{2)}$ \\ ${ }^{1}$ Fakultas MIPA dan Kesehatan Universitas Muhammadiyah Riau email : maswarni@umri.ac.id \\ 2 Ilmu Kesehatan Masyarakat STIKes Hangtuah Pekanbaru email : hayana.yana1986@gmail.com
}

\begin{abstract}
Spiritual Emotional Freedom Technique (SEFT) Therapy is a therapy that is carried out at a certain point on a part of the body or commonly called knock therapy. The purpose of doing this therapy is wrong to reduce blood pressure in hypertensive patients. Hypertension is an increase in blood pressure in the arteries. The purpose of this research is to see whether there is an influence of Emotional Freedom Technique (SEFT) Spiritual Therapy on blood pressure in Pandau Jaya Village. In this study using a quasi - pre and post experimental design of the design control group with the number of respondents 64 people divided into two groups, namely the comparison group number of respondents 32 people and in the control group the response number is 32 people. The instrument in this study consisted of a mercury tension meter and a stethoscope. Sampling using a purposive sampling using statistical tests. The test is dependent (paired-sample t test) to find out whether there are changes related to blood pressure selemu and done when doing therapy. This study uses a 95\% confidence level and a significance level of 0.05. Results: Research results in this case showed a P-value of 0,000 $(P<0.05)$, which means that there is an effect of SEFT therapy on systolic and diastolic blood pressure in hypertensive patients
\end{abstract}

Keywords: seft therapy, blood pressure, hypertension

\begin{abstract}
ABSTRAK
Terapi Spiritual Emotional Freedom Technique (SEFT) adalah suatu terapi yang melakukan penekanan pada titik tertentu pada bagian tubuh atau biasa di sebut terapi ketuk. Tujuan di lakukan terapi ini salah satunya untuk menurunakn tekanan darah pada pasien hipertensi. Hipertensi merupakan suatu peningkatan teknan pada darah di dalam arteri. Tujuan dari peneltian ini melihat apakah ada pengaruh Terapi Spiritual Emotional Freedom Technique (SEFT) pada penurunan tekanan darah di Desa Pandau Jaya. Desain yang di gunakan pada penelitian ini yaitu quasi-eksperimental dimana jumlah reponden 64 orang dan di bagi menjadi dua kelompok yaitu kelompok kontrol dengan jumlah 32 orang responden dan kelompok intervensi dengan jumalh 32 orang responden yang bertujuan untuk melihat hasil perbandingan kelompok kontrol dan kelompok intervensi pada penderita hipertensi sebelum dan sesudah di berikan terapi SEFT, Instrumen pada peneliltian ini terdiri dari set tensi meter air raksa dan stetoskop. Pengambilan sample menggunakan purposive sampilng dengan menggunakan uji statistik Uji dependent(paired-sample t test) untuk mengetahui apakah terdapat perubahan yang bermakna antara tekanan darah selemu dan sesudah di lakukan terapi. Penelitian ini menggunakan tingkat kepercayaan CI 95\% dan tingkat kemaknaan 0.05. Hasil: Hasil pada penelitian in terdapat menunjukkan bahwa nilai-P $=0,000(\mathrm{P}<0,05)$, yang berarti ada pengaruh terapi SEFT terhadap penurunan tekanan darah sistole dan diastole pada pasien hipertensi
\end{abstract}

Kata kunci : Terapi SEFT, Tekanan Darad, Hipertensi 


\section{PENDAHULUAN}

Penyakit tekanan darah tinggi (Hipertensi) merupakan suatu keadaan atau penyebab terjadinya kematian karena penyumbatan pembuluh darah (stroke) serta faktor yang lebih berat seperti serangan jantung. Gangguan yang paling sering terjadi yaitu gangguan asimtomatik dengan terjadi peningkatan tekanan darah yang terjadi secara persisten ${ }^{1}$

Hiperetnsi juga di artikan suatu tekanan darah yang persisten yang mana terjadi tekanan dari sistolik di atas $140 \mathrm{mmHg}$ dan peningkatan tekanan dari distolik $90 \mathrm{mmHg}$. Angka kejadian penyakit menular di Indonesia mengalami peningkatan, angka kejadian pada penyakit tidak menular juga mengalami peningkatan yaitu hipertensi yang mendapat sebutan juga the silent killer. ${ }^{3}$ pasien hipertensi selalu meningkat di setiap tahunnya. Berdasarkan survei oleh Badan Organisasi Kesehatan Dunia ( WHO) pada tahun 2011 ada terdapat sekitar 972.000 .000 orang ( $26,4 \%$ ) penduduk di dunia yang mengalami Hipertensi dengan nilai banding angka pada pria $26.6 \%$ dan pada wanita $26,1 \%$ dan sangat memungkin terjadi peningkatan pada tahun 2025 menjadi $29,2 \%$ pertahun. Pada negara maju terjadi penderita hipertensi berkisar 333.000.00 jiwa sedangkan di negara berkembang berkisar sekitar 639.000 .000 jiwa penduduk dan 8.000 .000 jiwa hampir terbunuh setiap tahunnya dimana 1,5 juta adalah penduduk Asia Tenggara ${ }^{4}$

Di Indonesia berdasarkan Riset Kesehatan Dasar pada tahun 2013 terdapat kasus hipertensi yang umur $\geq 18$ tahun sebesar 25,8 $\%$ dan terdapat $63,2 \%$ kasus hipertensi yang terjadi masyarakat tidak terdiagnosis dan ini menyebabkan kematian sebesar $6.8 \%$. Hal ini terjadi di sebabkan oleh tidak tersedianyaa sarana dan prasarana dalam penatalaksanaa hipertensi ${ }^{5}$. Bebarapa hal yang menyebabkan tingginya angka kejadian hipertensi adalah karena kebiasan merokok, aktifitas yang sedikit, pola makan yang tidak sesuai dengan kesehatan, kegemukan dan banyak pikiran. Di Provinsi Riau sendiri melihat data yang ada di
Dinas Kesehatan Kota Pekanbaru pada 2014, pada tahun 2012 penderita berjumlah sebanyak 19.878 orang, terjadi peningkatan pada tahun 2013 sebanyak 24.509 orang dan terjadi penurunan menjadi 20.601 pada tahun $2014^{4}$

Pada penderita hipertensi terdapat beberapa gangguan seperti merasa tajut dan cemas akan penyakitnya tidak sembuh i tambah dengan adanya beberapa komplikasi ${ }^{6}$. Pada orang hipertensi biasanya memilik emosi labil yang bisa membuat tekanan darah menjadi naik ${ }^{7}$

Menurut Gunawan (2001) cara penangan hipertensi ada 2 yaitu secara farmakologi dan non farmakologis. Terapi yang memakai obat di sebut dengan terapi farmakologi seperti menggunakan obat antihipertensi dan biasanya di kombinasikan dengan menggunkan terapi non farmakologis seperti tindakan komplementer, bahkan intervensi spiritual yang sudah mulai berkembang pada saat ini sehinggan membuat pengobatan hipertensi bukan hanya pada aspek biologis tapi bisa berkembang ke aspek psikis dan spritual ${ }^{8}$

Terapi spiritual emotional freedom technique (SEFT) adalah suatu terapi yang berupa gabungan dari sistem energy pada (energy medicine) dan terapi Spritual gabungan tapping pada titik yang sudah tentukan pada beberapa bagian tubuh yang hampir sama dengan tehnik akupuntur dan akupresur dengan merangsang beberapa titik titik kunci pada sepanjang 12 jalur energi (energy meridian) tubuh. Hal yang menjadi pembeda terapi SEFT, akupuntur dan akupresur adalah pada terapi SEFT menambahkan unsur spiritual, yang lebih terkesan aman dan mudah untuk di gunakan digunakan sert lebih sederhana karena hanya menggunakan beberapa kali ketukan tangan (tapping) ${ }^{2}$ 


\section{METODE PENELITIAN}

Desain yang di gunakan pada penelitian ini yaitu quasi-eksperimental dimana jumlah reponden 64 orang dan di bagi menjadi dua kelompok yaitu kelompok kontrol dengan jumlah 32 orang responden dan kelompok intervensi dengan jumalh 32 orang responden yang bertujuan untuk melihat hasil perbandingan kelompok kontrol dan kelompok intervensi pada penderita hipertensi sebelum dan sesudah di berikan terapi SEFT, sedangkan untuk instrumen yang di pakai dalam penelitian ini yaitu lembar observasi dengan menggunakan alat yang terdiri dari tensi meter air raksa, stetoskop untuk tehink tehnik pengambilan sample menggunakan purvosive sampling Pada penelitian ini digunakan ujistatistik

\begin{tabular}{lcccc} 
& digunakan & ujistatistik & Uji & t \\
\hline Variabel & Intervensi & $\mathbf{n}$ & Mean (mmHg)
\end{tabular}

TD Sistole

Sebelum

$\begin{array}{lrr}2 & 158,25 & \\ 32 & & 146,12\end{array}$

Sesudah

32

146,12 dependent(paired-sample t test) untuk mengetahui apakah ada perubahan yang bermakna antara nilai tekanan darah sebelum dan sesudah terapi SEFT, baik tekanan darah sistolik maupun tekanan darah diastolik. Dalam penelitian ini menggunakan tingkat kepercayaan CI $95 \%$ dan tingkat kemaknaan 0.05 .

\section{HASIL DAN PEMBAHASAN}

1. Perbandingan Tekanan Darah Sebelum Dan Sesudah Diberikan Terapi SEFT untuk kelompok Intervensi

Table 1.1 Perbandingan Tekanan Darah Sebelum di berikan Dan Sesudah Diberikan Terapi SEFT untuk kelompok Intervensi

\begin{tabular}{lllllll} 
TD Diastole & Sebelum & 3 & 98,18 & 4,61 & 11,88 & 0,000 \\
\hline & 2 & & & $\mathbf{3 , 9 2}$ & $\mathbf{0 , 0 0 0}$
\end{tabular}

Pada tabel 1.1 dapat dilihat nilai rata-rata sistole sebelum dilakukan terapi pada kelompok intervensi $158 \mathrm{mmHg}$ dan standar deviasi $6,53 \mathrm{mmHg}$, diastolenya 98, 18 $\mathrm{mmHg}$ dengan nilai standar deviasi 4,61 $\mathrm{mmHg}$ sedangkan rata-rata sistole pada kelompok intervensi sesudah diberikan terapi SEFT yaitu 146, $12 \mathrm{mmHg}$ dengan nilai standar deviasi 7,25 $\mathrm{mmHg}$ dan untuk diastolenya yaitu $87,37 \mathrm{mmHg}$ dengan standar deviasinya $3,92 \mathrm{mmHg}$

Berdasarakan hasil analisis dengan menggunakan Uji t, menujukkan bahwa nilai $\mathrm{t}$ hitung pada tekanan sistole sebesar 16,65 dengan $p$-value
0,000, sedangkan untuk $\mathrm{t}$ hitung pada tekanan diastole 11,88 dan $\mathrm{p}$ value 0,000 terlihat tabel di atas bahwa p-value tersebut lebih kecil dari $\alpha \quad(0,05)$. Hal ini memperlihatkan terdapat perbedaan yang yang terjadi pada tekanan sistole maupun tekanan distole pada kelompok intervensi sebelum dan sesudah dilakukan terapi SEFT secara signifikan

2. Perbandingan Tekanan Darah Sebelum Dan Sesudah tanpa diberikan perlakuan Terapi SEFT untuk kelompok Kontrol

Tabel 2.1 Perbandingan Tekanan Darah Sebelum Dan Sesudah tanpa Diberikan perlakuan Terapi SEFT untuk kelompok Kontrol 


\begin{tabular}{lllllll}
\hline Variabel & Kontrol & n & $\begin{array}{l}\text { Mean } \\
(\mathbf{m m}\end{array}$ & $\begin{array}{l}\text { SD } \\
(\mathbf{m m H}\end{array}$ & t & $p$ \\
& & Hg) & g) & &
\end{tabular}

\begin{tabular}{|c|c|c|c|c|c|c|}
\hline \multirow{2}{*}{$\begin{array}{r}\text { TD } \\
\text { Sistole }\end{array}$} & Sebelum & 32 & $\begin{array}{l}157,8 \\
1\end{array}$ & 4,15 & 0,304 & 0,763 \\
\hline & Sesudah & 32 & 157,4 & 4,90 & & \\
\hline
\end{tabular}

$\begin{array}{ccccccc}\text { TD } & \text { Sebelum } & 32 & 95,31 & 6,86 & -, 600 & 0,553 \\ \text { Diastole } & & & & & & \\ & \text { Sesudah } & 32 & 96,25 & 5,376 & & \end{array}$

Pada tabel 2.1 dapat dilihat nilai rata-rata sistole responden sebelum diberikan perlakuan pada kelompok kontrol sebesar 157,81 mmHg dengan standar deviasi 4,15 $\mathrm{mmHg}$, tekanan diastole responden 95,31 $\mathrm{mmHg}$ dengan standar deviasi 4,15 mmHg sedangkan untuk rata-rata tekanan sistole pada responden kelompok kontrol tanpa diberikan perlakuan/tindkan sebesar 157,43 mmHg dengan standar deviasinya 4,90 $\mathrm{mmHg}$ dan untuk tekanan diastolenya responden sebesar 96,25 $\mathrm{mmHg}$ dengan standar deviasinya $5,37 \mathrm{mmHg}$

Berdasarakan hasil analisa data dengan menggunakan $\mathrm{Uji} t$, menujukkan bahwa nilai $t$ hitung untuk sistole sebesar 0,304 dengan $p$-value 0,763 , sedangkan untuk $t$ hitung pada diastole -600 dan p-value 0,553 . pada tabel di atas menunjukka bahwa $p$ value tersebut lebih besar dari $\alpha$ $(0,05)$. Dengan demikian terlihat tidak terdapat perbedaan yang brmakna baik pada tekanan sistole maupun tekanan distole pada kelompok kontrol sebelum dan sesudah dilakukan terapi SEFT

Dilihat dari hasil penelitian
yang dilakukan kepada kedua
kelompok yaitu pada kelompok
intervensi (dengan perlakuan/tindakan)

dan pada kelompok kontrol (tidak dengan perlakuan/tindakan ) di dapati hasil pada kelompok intevensi responden yang diberikan terapi spiritual emotional freedom technique (SEFT) mengalami perubahan penurunan tekanan darah secara signifikan sedangkan pada kelompok kontrol yang tidak di berikan perlakuan tidak mengalami penurunan tekanan darah yang bermakna. Berdasarkan hal ini menunjukkan ternyata ada pengaruh terapi SEFT terhadap penurunan tekanan darah pada kelompok intervensi

Menurut Thayib (2010), dengan melakukan stimulasi terhadap titik-titik meridian tubuh selama lebih kurang 10-15 menit dengan intensitas ketukan yang sama maka bisa membantu mengurangi tingkat kecemasan dan perasaan bisa terasa lebih tenang. Selain itu terapi SEFT ini juga menstimulus mengelurakan hormon endorfin yang berfungsi sebagai hormon kebahagiaan sehingga bisa membuat seseorang lebih merasa nyaman. ${ }^{9}$

Lane, (2009), menyatakan memberi stimulasi yang dilakukan secara manual pada titik akupuntur berfungsi membantu mengontrol kortisol. Berdasarkan penelitian yang dilakukan oleh Dawson, Garrret \& audrey (2012) dalam the Journal of Nervous and Mental Disease yang memakai EFT untuk menurunkan kortisol pada orang yang memiliki stress. Menurut hasil penelitian tersebut EFT mampu turun kadar kortisol sebesar -24.39 $\%$. 10

Pada Penelitian Zulaichah (2013) dengan judul "Pengaruh Terapi SEFT Terhadap Penurunan 
Tekanan Darah Pada Lansia Hipertensi di Puskesmas Jagir Surabaya" yang dilakukan pada 15 responden yang dibagi dalam dua kelompok eksperimen dan kelompok kontrol menunjukkan terdapat pengaruh terapi SEFT terhadap tekanan darah penderita hipertensi di Puskesmas Jagir Surabaya, dengan $p$ value $0,000<\alpha$ $0.05 .^{4}$

Senada juga dengan Nurfaridah (2012) dengan judul "Pengaruh Terapi SEFT Islami Terhadap Tekanan Darah Pada Penderita Hipertensi Usia 45-59 Tahun di RSUD Dr. Soegiri Lamogan" yang laksanakan kepada 30 orang responden memperlihatkan terapi SEFT ini terdapat pengaruh pada tekanan darah pasien hipertensi di RSUD Dr. Soegiri Lamogan, dengan nilai $p$ value $0,000<\alpha 0,05$. $^{4}$ sedangkan menurut penelitian yang dilakukan oleh Teti (2013) memperlihatkan terdapatnya penurunan tekanan darah diastolik sesudah dilakukan terapi SEFT ini . ${ }^{11}$

Menurut Hasil penelitian Sunardi dkk. (2014), mendukung hasil penelitian di atas. terapi SEFT efektif menurunkan tekanan darah responden yang menderita hipertensi di dapati hasil uji t-test Independent pada tekanan darah sistolik dengan nilai $\mathrm{p}$ value $0,023(\mathrm{P}<0,05)^{12}$

Pada Terapi Spiritual Emotional Freedom Technique (SEFT)ini dapat membantu mengatasi berbagai masalah diantaranya masalah emosi, masalah fisik yang dialami oleh seseorang misalnya dismenorea, dengan terapi SEFT dapat mengurangi rasa nyeri pada penderita dismenora, bahkan bisa menghlangkn rasa nyeri dalam yang waktu yang tidak terlalu lama.. Hal ini dapat terjadi karena terapi ini lebih menekankan pada unsur spiritual dan sistem energi tubuh dengan menggunakan metode tapping pada beberapa titik tertentu pada tubuh. Selain sistem energi tubuh, metode relaksasi juga dapat dilakukan dengan melibatkan faktor keyakinan pasien yang bahwa terapi SEFT dapat menurukan tekanan darah ${ }^{13}$

\section{SIMPULAN}

Terapi SEFT adalah salah satu terapi modalitas yang efektif menurunkan tekanan darah pada penderita hipertensi. Terapi SEFT ini sangat mudah di pelajari oleh siapapun bisa di pelajari secara otodidak setelah itu bisa di sosialisasikann kepada masyarakat luas Terapi SEFT ini juga bisa dilakukan kapan saja dan oleh siapa saja. Dalam kajian yang luas terapi SEFT ini juga digunakan pada penyakit mental seperti stres dan depresi, mereka juga dijangkiti penyakit fisik yang cukup berat seperti, alergi, maag, migrain, dll. Terapi SEFT ini bisa dikembangkan pada tingkatn lebih lanjut.Berdasarkan penelitian ini dapat di simpulkan bahwa ada pengaruh terapi spiritual emotional freedom technique (SEFT) pada penurunan tekanan darah penderita hipertensi di Desa Pandau Jaya kecamatan Siak Hulu kabupaten kampar dengan p-value 0,000 $<\alpha 0.05$ pada systole dan pada diastole p-value $0.000<\alpha 0,05$

\section{DAFTAR PUSTAKA}

Ahmad FZ (2010). SEFT Spiritual Emotional Freedom Technique seputar aplikasi Praktis untuk Penyembuhan.

Dawson Church, (2012).,Garret Yount, and Audrey J. Brooks, P. The Effect of Emotional Freedom Techniques on Stress Biochemistry. J. Nerv. Ment. Dis. 200, 1-6 
Deby, S. (2015) Technique (Seft) Terhadap Penurunan Tekanan Darah Pada Penderita Hipertensi Di Wilayah Kerja Puskesmas Pauh Kota Padang. Tesis Fak. Keperawatan UNAND

Julianty, P. (2010). Faktor-faktor yang mempengaruhi terjadinya hipertensi di daerah perkotaan. Gizi Indones Press Jakarta.

Kemenkes.RI. (2014). Pusdatin STROKE. Pusat Data Dan Informasi Kementrian Kesehatan doi:10.1177/109019817400200403

Murni. (2018) Efektivitas Terapi Spritual Emotional Freedom Technique (Seft ) Terhadap Penurunan Tekanan Darah. Jurnal Photon 8, 151-158 . Umri Pekanbaru

Noerhadi, M. (2008) Hipertensi Dan Pengaruhnya Terhadap OrganOrgan Tubuh. Jurnal Medikora 4, $1-18$

Rofacky, H. F. dan F. A. (2015). Pengaruh Terapi Spiritual Emotional Freedom Technique (SEFT) Terhadap Tekanan Darah Penderita Hipertensi. J. Keperawatan Soedirman (The Soedirman J. Nursing) 2, 17-23

RI, K. K. (2015) Hipertensi The Silent Killer. Pusat Data dan Informasi Kementrian kesehatan Republik Indonesia

Sunardi, Purwanto, E. \& Sakinah, T. (2014). Efektifitas Terapi Seft Dalam Menurunkan Hipertensi J. Ners dan Kebidanan 1, 97-102

Tarigan, A. R., Lubis2, Z. \& Syarifah. (2018) Pengaruh pengetahuan, sikap dan dukungan kelaurga terhadap diet hipertensi di Desa Hulu Kecamatan Pancur Batu Tahun 2016. J. Kesehat. 11, 9-17

Teti dan Subiayanto. (2013). Emotional Freedom Techniques Dapat Penurunan Tekanan Darah. Media Ilmu Kesehatan

Thayib, S. . 2010) Preview Spiritual
Emotional Freedom Technique. Institute:LoGOS 